\title{
APROVEITAMENTO DE SILÍCIO PROVENIENTE DE ESCÓRIA SIDERÚRGICA POR CULTIVARES DE CANA-DE-AÇÚCAR ( ${ }^{(1)}$
}

\author{
ROBSON THIAGO XAVIER DE SOUSA $\left(2^{*}\right)$; GASPAR HENRIQUE KORNDÖRFER $(3,5)$; \\ DALCIMAR REGINA BATISTA WANGEN $(4,5)$
}

\begin{abstract}
RESUMO
A cana-de-açúcar é uma espécie acumuladora de silício (Si), capaz de responder à adubação silicatada, principalmente, em solos pobres desse elemento. As escórias de siderurgia constituem em uma interessante fonte de Si para aplicação em solos cultivados com essa cultura. Objetivou-se estudar o aproveitamento do Si proveniente da escória siderúrgica pela cana-de-açúcar. O experimento foi desenvolvido em Uberlândia (MG), entre 15 de agosto de 2007 e 2 de maio de 2008. O delineamento experimental utilizado foi o de blocos ao acaso em esquema fatorial 2x4, sendo duas cultivares de cana-de-açúcar (SP81 - 3250 e RB86 - 7515) e quatro doses de Si (0, 100, 200 e $400 \mathrm{~kg} \mathrm{ha}^{-1}$ ) em quatro repetições. A cana foi cultivada em tambores plásticos (200 L). A aplicação de escória de siderurgia (silicato) aumentou o teor de Si disponível no solo e o teor foliar da cana-de-açúcar. A quantidade de Si acumulada pela parte aérea da cana proveniente do silicato aplicado variou entre $23 \%$ e $56 \%$, respectivamente, para as variedades RB86-7515 e SP81-3250. Em média, 39\% do Si absorvido pela parte aérea da cana foram provenientes do fertilizante aplicado (silicato).
\end{abstract}

Palavras-chave: silicato, Si solúvel, recuperação de silício, Si acumulado.

\section{ABSTRACT \\ RECOVERY OF SILICON FROM METALLURGY SLAG BY SUGARCANE CULTIVARS}

Sugarcane is a species that accumulates silicon ( $\mathrm{Si}$ ) and is capable of responding to Si applications, especially in soils lacking Si.. Metallurgy slag is an interesting source of Si for soils cultivated with this crop. The aim of this study was to evaluate the recovery of Si from metallurgy slag by sugarcane. The experiment was carried out at Uberlândia-MG, from August 15, 2007 to May 02, 2008. The experimental design was randomized in a $2 \times 4$ factorial arrangement being two cultivate of sugarcane (SP81 - 3250 and RB86 - 7515) and four Silicon doses (0, 100, 200 and $400 \mathrm{~kg} \mathrm{ha}^{-1}$ ) with four replications. The sugarcane was cultivated in plastic drums (200 L). The application of slag (silicates) increased the content of available silicon in soil and leaf of sugarcane. The amount of Si accumulated in the aerial part of sugarcane from the silicate applied ranged between 23 and 56\% respectively for the variety RB867515 and SP81-3250. On average, 39\% of Si absorbed by the shoot of the sugarcane came from the fertilizer applied (silicate).

Key word: silicate, soluble Si, silicon recovery, accumulated Si.

(1) Recebido para publicação em 9 de outubro de 2008 e aceito em 21 de janeiro de 2010.

(2) Mestrando em Agronomia, Universidade Federal de Uberlândia, Rua Amazonas s/n, Laboratório de Fertilizantes, Caixa Postal 593, 38400-902 Uberlândia (MG); E-mail: robsontxs@yahoo.com.br. (*) Autor correspondente.

(3) Universidade Federal de Uberlândia - UFU, Instituto de Ciências Agrária/ICIAG. E-mail: ghk53@terra.com.br

$\left(^{4}\right)$ Doutoranda em Agronomia na Universidade Federal de Uberlândia - UFU, Instituto de Ciências Agrárias/ICIAG. E-mail: drbwangen@ yahoo.com.br.

(5) Bolsista CNPq. 


\section{INTRODUÇÃO}

Atualmente, a cana-de-açúcar destaca-se não apenas pela sua importância como fonte de matériaprima para a produção de açúcar, mas, particularmente, por se constituir em insumo básico para a produção do etanol que abastece os automóveis e ajuda a romper o domínio dos combustíveis fósseis sobre nossa sociedade (JAN, 2008). O Brasil destaca-se no cenário mundial como o maior produtor de cana-de-açúcar (BRASIL...2007). No entanto, muitas das áreas sob cultivo dessa cultura no país caracterizam-se pelos solos bastantes intemperizados e, portanto, pobres em silício (Si) solúvel ou disponível às culturas.

A cana-de-açúcar é uma espécie acumuladora de $\mathrm{Si}$, com $0,14 \%$ desse elemento nas folhas jovens até $6,7 \%$ nos colmos e folhas velhas (KORNDÖRFER e DATNOFF, 1995). Diversos estudos (Pereira et al., 2004; Carvalho-Pupatto, 2003; Berni e PrabHu, 2003) têm demonstrado que as gramíneas respondem favoravelmente à adubação silicatada, particularmente quando cultivada em solos com baixos teores de Si "disponível".

Vários são os benefícios do Si para a canade-açúcar, dentre os quais, o aumento da eficiência fotossintética e da resistência ao ataque de pragas e doenças, maior tolerância à falta de água durante os períodos de baixa umidade do solo (KORNDÖRFER e DATNOFF, 1995), alívios de danos causados por geada e da melhoria da arquitetura das plantas (SAVANT et al., 1999), dentre outros. Tais benefícios têm como reflexos melhorias na qualidade tecnológica e nos aumentos de produtividade dessa cultura.

As escórias siderúrgicas, provenientes da produção do aço e do ferro-gussa, constituídas basicamente de silicatos de cálcio e magnésio, desde que não se constituam em fontes de contaminação do solo com metais pesados, podem atender satisfatoriamente a características ideais como fonte de Si para uso agrícola que são: alto conteúdo de Si solúvel, facilidade de aplicação mecanizada, adequadas relaçõese quantidades de cálcio (Ca) e magnésio $(\mathrm{Mg})$, custo reduzido e baixo potencial de contaminação do solo com metais pesados. (KORNDÖRFER et al., 2004).

Embora o aproveitamento agrícola de resíduos industriais, como as escórias de siderurgia, seja pouco comum no Brasil, apesar da grande quantidade disponível, seu uso no fornecimento de Si para as plantas é estudado e praticado em várias partes do mundo (Prado e FernANDES, 2001).

Considerando que parte do silício absorvido/ acumulado pelas plantas é proveniente do solo e parte proveniente do $\mathrm{Si}$ aplicado na forma de fertilizante, objetivou-se neste trabalho avaliar as diferenças varietais quanto à absorção de Si e a quantidade de Si acumulado na parte aérea proveniente da escória de siderúrgica.

\section{MATERIAL E MÉTODOS}

O experimento foi desenvolvido em Uberlândia (MG), simulando situação de campo, no período de 15 de agosto de 2007 a 2 de maio de 2008. O delineamento experimental utilizado foi o de blocos ao acaso em quatro repetições com esquema fatorial $2 \times 4$, sendo duas cultivares de cana-de-açúcar (SP81 - 3250 e RB86 - 7515) e quatro doses de $\mathrm{Si}\left(0,100,200\right.$ e $\left.400 \mathrm{~kg} \mathrm{ha}^{-1}\right)$, aplicandose, para ambas cultivares, respectivamente, escória de siderurgia nas doses de 0, 890, 1779 e $3559 \mathrm{~kg} \mathrm{ha}^{-1}$. Visando evitar a variação do $\mathrm{pH}$ do solo, proporcionada pelas doses de escória, aplicou-se, respectivamente, a essas doses de escória, calcário dolomítico nas quantidades de 3559, 2669, 1779 e $0 \mathrm{~kg} \mathrm{ha}^{-1}$.

$\mathrm{Na}$ escória de siderurgia $\left(\mathrm{CaSiO}_{3}\right)$ utilizada, observaram-se as seguintes características físicas e químicas: formulação pó, PRNT: $85 \%$, CaO: $420 \mathrm{~g} \mathrm{~kg}^{-1}$, MgO: $120 \mathrm{~g} \mathrm{~kg}^{-1}, \mathrm{SiO}_{2}: 230 \mathrm{~g} \mathrm{~kg}^{-1}, 112 \mathrm{~g} \mathrm{~kg}^{-1} \mathrm{Si}$ total (determinado por colorimetria após a extração com ácido clorídrico e ácido fluorídrico, segundo metodologia descrita por Korndorfer et al 2004a, $\mathrm{P}_{2} \mathrm{O}_{5}: 4 \mathrm{~g} \mathrm{~kg}^{-1}, \mathrm{~K}_{2} \mathrm{O}: 2$ $\mathrm{g} \mathrm{kg}^{-1}, \mathrm{SO}_{4}: 44 \mathrm{~g} \mathrm{~kg}^{-1}$, Fe: $85 \mathrm{~g} \mathrm{~kg}^{-1}, \mathrm{Mn}: 14 \mathrm{~g} \mathrm{~kg}^{-1}$, Mo: 0,4 $\mathrm{mg} \mathrm{kg}^{-1}$ e Zn: $0,1 \mathrm{mg} \mathrm{kg}^{-1}$.

Cada parcela experimental consistiu de um tambor de plástico, com capacidade para $200 \mathrm{~L}$, preenchido com $200 \mathrm{~kg}$ de terra e três touceiras de cana-de-açúcar. A terra utilizada nos tambores foi extraída dos primeiros $20 \mathrm{~cm}$ superficiais de um solo classificado como Latossolo Vermelho Distrófico típico A moderado, textura média, fase cerrado tropical subcaducifólio, relevo suave ondulado (EMBRAPA, 2006), situado no município de Uberlândia-MG, com as seguintes características químicas: matéria orgânica $=13 \mathrm{~g} \mathrm{dm}^{-3} ; \mathrm{pH}$ em $\mathrm{CaCl}_{2} 0,01 \mathrm{~mol} \mathrm{~L}^{-1}(1: 2,5)=5,2 ; \mathrm{P}$ $\mathrm{Meh}^{-1}=2,7 \mathrm{mg} \mathrm{dm}^{-3} ; \mathrm{K}=1 ; \mathrm{Ca}=7,0 ; \mathrm{Mg}=3,0 ; \mathrm{H}$ $+\mathrm{Al}=31,0$ todos trocáveis em mmolc $\mathrm{dm}^{-3} \mathrm{e} \mathrm{V}=27$ $\%$, (EMBRAPA, 1999). O Si solúvel no solo, $4,3 \mathrm{mg} \mathrm{dm}^{-3}$, foi determinado segundo metodologia descrita por KoRNDORFER et al. (2004a), utilizando como extrator o $\mathrm{CaCl}_{2} 0,01 \mathrm{~mol} \mathrm{~L}^{-1}$.

Anteriormente ao transplantio das mudas de canade-açúcar para os tambores, foram aplicadas quantidades pré-estabelecidas de calcário, com características físicas e químicas semelhantes às da escória utilizada (PRNT $85 \%, \mathrm{CaO}=420 \mathrm{~g} \mathrm{~kg}^{-1}$ e $\mathrm{MgO}=120 \mathrm{~g} \mathrm{~kg}^{-1}$ ), a fim de se evitar que as plantas que receberam doses maiores de escória fossem favorecidas em função do $\mathrm{Ca}$ e $\mathrm{Mg}$ presente, em detrimento daquelas que receberam doses menores do produto. 
Com o intuito de se fornecer nutrientes em quantidades suficientes para atender a demanda das plantas de cana-de-açúcar, aplicaram-se, em todos os tratamentos, $100 \mathrm{~kg} \mathrm{ha}^{-1}$ nitrogênio $(\mathrm{N}) ; 300 \mathrm{~kg} \mathrm{ha}^{-1}$ fósforo $\left(\mathrm{P}_{2} \mathrm{O}_{5}\right)$ (Sulfato de Amônio e Superfosfato Simples), $300 \mathrm{~kg} \mathrm{ha}^{-1}$ potássio $\left(\mathrm{K}_{2} \mathrm{O}\right)$ (Cloreto de Potássio $-\mathrm{KCl}) ; 80 \mathrm{~kg} \mathrm{ha}^{-1}$ de um coquetel de micronutrientes (FTE - BR12), com a seguinte composição, $9 \%$ Zn; 1,8\% B, 2\% Mn, 0,8\% Cu, 0,1\% Mo e 3\% Fe (RAIJ, , 1996).

A quantidade de terra empregada em cada tambor foi dividida em duas porções de $100 \mathrm{~kg}$ cada, tendo-se incorporado em uma delas os nutrientes (macro e micronutrientes). Em seguida, essa terra foi colocada no fundo do tambor. À segunda porção de terra foram incorporados os nutrientes, o calcário e a escória, e depois colocou-se dentro do vaso, sobre a primeira porção. Esse procedimento foi adotado para distribuir uniformemente os nutrientes por todo o tambor e deixar o calcário e o silicato apenas na primeira camada do solo. O próximo passo consistiu da adição de água na terra contida no tambor, até que se atingisse cerca de $70 \%$ da capacidade de campo (tendo-se empregado aproximadamente $32 \mathrm{~L}$ de água por vaso), a fim de se promover a reatividade dos produtos adicionados à terra.

As gemas que deram origem às mudas de cana foram plantadas em 15 de agosto de 2007 e transplantadas 13 de setembro do mesmo ano (cerca de um mês após a germinação). Foram transplantadas três mudas por tambor. Em 10 de dezembro de 2007, 87 dias após o transplantio das mudas, constatou-se deficiência de boro (B) nas plantas e foram aplicados $2,0 \mathrm{~kg} \mathrm{ha}^{-1} \mathrm{de}$ ácido bórico por vaso. Em 17 de dezembro de 2007, após constatar deficiência de nitrogênio, foram aplicados 200 $\mathrm{kg} \mathrm{ha}^{-1}$ de N, sob a forma de sulfato de amônio $(20 \%$ de N), e em 21 de dezembro de 2007, novamente, $2 \mathrm{~kg}$ ha-1 de ácido bórico. Em janeiro de 2007, fez-se avaliação visual de deficiência de boro e foram coletadas folhas (primeira folha do ápice para a base com a lígula visível - TVD ou Top Visible Dewlep) (Korndorfer e RAmos, 2008) para análise do teor foliar de Si. Nesta mesma, aos 120 dias após o transplantio das mudas, foram retiradas amostras de solo para análise de Si disponível ou solúvel.

A colheita da cana-de-açúcar foi realizada manualmente, em 2 de maio de 2008, oito meses após o transplantio das mudas. Logo após o corte, as plantas foram divididas em ponteiro (palmito + folhas) e colmos, os quais foram pesados. Os materiais vegetais foram moídos separadamente e colocados para secar em estufa de circulação de ar, sob temperatura de $65^{\circ} \mathrm{C}$, até atingirem massa constante. Após seco, cada um dos três materiais foi novamente moído, em moinho tipo Willey, e acondicionado em saco plástico devidamente identificado e armazenado até ser submetido à análise para determinação do teor de Si.

A acumulação de Si pelas plantas foi estimada a partir da produção de matéria seca por parte das plantas e pelo teor foliar de Si. Para determinação do Si na parte aérea das plantas, adotaram-se procedimentos analíticos descritos por KORNDORFER et al. (2004a). Após a colheita da cana, aos 260 dias, coletaram-se amostras de terra de cada tambor para análise do Si solúvel, conforme KORNDORFER et al. (2004a); pH, Ca e Mg trocáveis, conforme EMBRAPA (1999).

Os resultados qualitativos foram submetidos à análise de variância. Quando do teste F significativo as médias foram comparadas entre si pelo teste de Tukey a 0,05 de significância, com o auxílio do programa SISVAR (FERREIRA, 2000). Os resultados quantitativos foram submetidos à análise de regressão, tendo-se empregado, para tanto, o programa estatístico SISVAR (FERREIRA, 2000).

\section{RESULTADOS E DISCUSSÃO}

Os teores de Si no solo aumentaram linearmente com as doses da escória, conforme se verificou nas análises realizadas aos 120 e 260 dias após a aplicação (Figura 1). A análise realizada aos 120 dias após a aplicação da escória revelou aumentos de 18, 56 e $72 \%$ nos teores de $\mathrm{Si}$, conforme se aplicaram 100, 200 e $400 \mathrm{~kg} \mathrm{ha}^{-1} \mathrm{Si}$, respectivamente, quando comparadas ao tratamento testemunha (dose zero de escória). Aos 260 dias, os teores de Si no solo nos tratamentos que receberam 100, 200 e $400 \mathrm{~kg} \mathrm{ha}^{-1} \mathrm{Si}$ eram de $2 \%$, 8\% e $50 \%$, respectivamente, superiores ao da testemunha (Figura 1). Nota-se que, cerca de nove meses após sua aplicação, a escória continuava a fornecer Si para o solo, embora em menores proporções nas doses de 100 e 200 $\mathrm{kg} \mathrm{ha}^{-1}$ de Si aplicado (Figura 1).

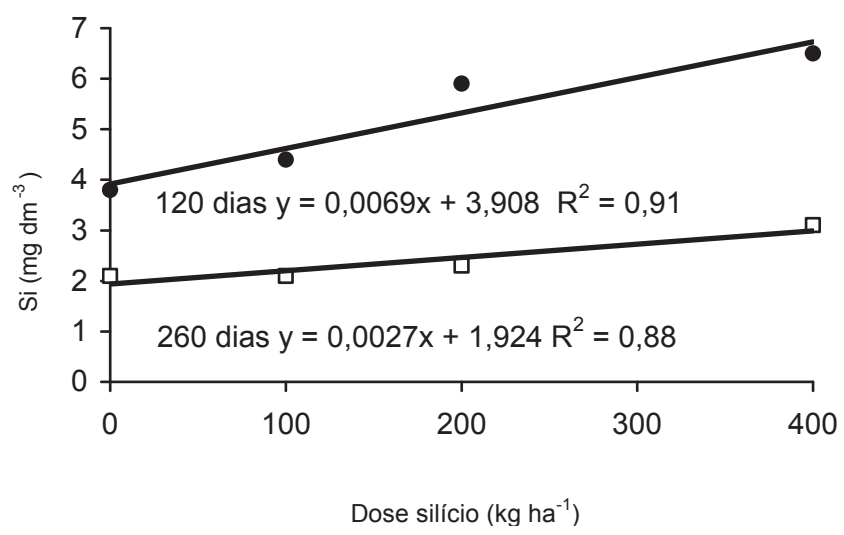

Figura 1. Concentração de Si no solo aos 120 e 260 dias após a aplicação de doses crescentes deSi. Cada símbolo representa o valor médio de oito repetições para cada dose. 
Tabela 1. Conteúdo de Si disponível no solo, Si acumulado na parte aérea da cana, Si absorvido proveniente do fertilizante e Índice de Recuperação, em função das doses de Si aplicadas (média das duas variedades)

\begin{tabular}{|c|c|c|c|c|c|}
\hline Si aplicado & $\begin{array}{l}\mathrm{Si} \text { "disponível” no } \\
\text { solo }\end{array}$ & $\begin{array}{l}\text { Si acumulado na } \\
\text { parte aérea }\end{array}$ & $\begin{array}{c}\text { Si absorvido } \\
\text { proveniente do } \\
\text { fertilizante* }\end{array}$ & $\begin{array}{c}\text { Índice de } \\
\text { Recuperação** }\end{array}$ & Média \\
\hline & $-\mathrm{g}$ & aso - & - & 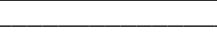 & 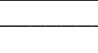 \\
\hline 0 & 0,42 & 12,31 & - & - & \multirow{4}{*}{39,4} \\
\hline 5 & 0,43 & 15,14 & 2,83 & 56,6 & \\
\hline 10 & 0,45 & 15,89 & 3,58 & 35,8 & \\
\hline 20 & 0,63 & 17,46 & 5,15 & 25,8 & \\
\hline
\end{tabular}

*Si absorvido proveniente do fertilizante = Si acumulado na parte aérea - Si acumulado pela testemunha;

**Índice de Recuperação $(\%)=($ Si absorvido proveniente do fertilizante/Si aplicado) x 100.

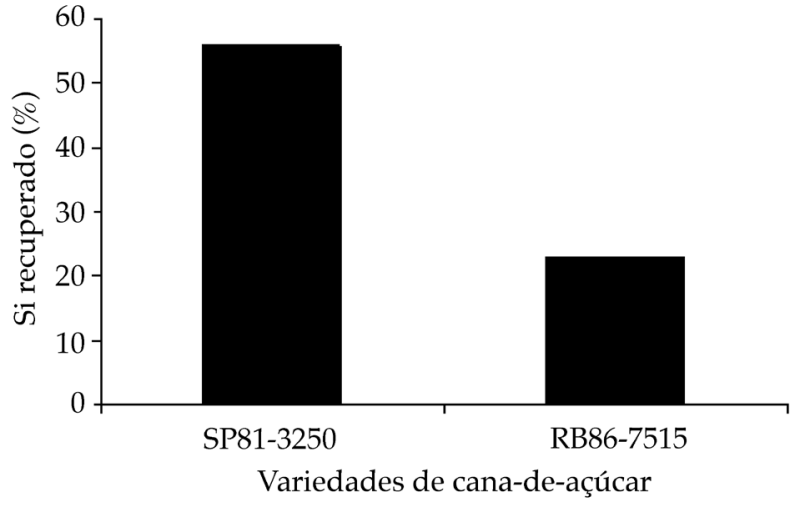

Figura 2. Silício recuperado pelas duas variedades de canade-açúcar. Cada barra representa o valor médio de 16 repetições para cada variedade.

Ao se compararem os dados das análises realizadas aos 120 e 260 dias após a aplicação da escória, verificou-se redução expressiva nos teores de Si no solo (Figura 1). Essa diferença pode ser explicada em parte pela extração do $\mathrm{Si}$ pela cana-de-açúcar (Tabela 1). Os teores de Si nas plantas aumentaram de 12,31 para 17,46 g por vaso quando a dose de Si aplicada foi de $400 \mathrm{~kg} \mathrm{ha}^{-1}$, o que corresponde a um aumento de aproximadamente $70 \%$ na quantidade de $\mathrm{Si}$ extraído pela parte aérea da cana (Tabela 1).

$\mathrm{O}$ aumento dos teores de $\mathrm{Si}$ no solo foi consequência da aplicação de doses de escória (Tabela 1). A disponibilidade de Si no solo aumentou linearmente, porém com pequenos incrementos, com o aumento das doses de escória, tendo partido de 0,42 g por vaso, na testemunha, para $0,63 \mathrm{~g}$ por vaso, com o fornecimento de $400 \mathrm{~kg} \mathrm{ha}^{-1} \mathrm{de} \mathrm{Si}$. Consequentemente houve acréscimo na quantidade de Si acumulado na planta, conforme se elevaram as doses de escória aplicada (Tabela 1).

A recuperação média do silicato pelas duas cultivares de cana-de-açúcar foi de $39,4 \%$, tendo variado de 25,8\% a 56,6\%, dependendo da dose aplicada (Tabela 1 ). Considerando-se o fato de que solo estudado havia baixos teores de argila e matéria orgânica e baixa capacidade de retenção de água, a interação das partículas do silicato com a fase sólida do solo foi menor, explicando, portanto, a baixa reatividade do silicato aplicado. Esse resultado está de acordo com aqueles reportados por KORNDÖRFER et al. (1999), os quais, estudando o efeito do silicato de cálcio como fonte de Si para a cultura do arroz de sequeiro, em quatro solos representativos da região do cerrado, verificaram maior recuperação desse elemento em solos com maiores teores de argila.

A cultivar de cana SP81-3250 foi a de maior capacidade de recuperação de Si (Índice de Recuperação de $55,8 \%$ ), isto é, do total de Si absorvido mais da metade foi proveniente do fertilizante. A diferença entre as quantidades de Si recuperado pelas duas cultivares foi da ordem de $60 \%$, o que demonstra com clareza a maior capacidade da cultivar SP81-3250 extrair esse elemento do solo, quando comparada com a cultivar RB86-7515, sob as mesmas condições de cultivo (Figura 2).

De maneira geral, a cultivar SP81-3250 foi superior em relação a RB86-7515, quanto à capacidade de acumular Si nos ponteiros (palmito+folhas), folhas abaixo dos ponteiros e colmos, o que resultou em maior acúmulo desse elemento na parte aérea total da planta (Tabela 2). Os teores médios de Si acumulados nos ponteiros (palmito+folhas), folhas abaixo dos ponteiros, colmos e parte aérea total da cultivar SP81-3250 foram de $80 \%, 29 \%$, $23 \%$ e $24 \%$ superior respectivamente, aos acumulados pela variedade RB86-7515 (Tabela 2).

Os teores médios de $\mathrm{Si}$ acumulados nas folhas, no colmo e, consequentemente, nas plantas das duas cultivares de cana aumentaram linearmente com as doses de Si aplicadas (Figuras 3a, b, c). Tal resultado reforça, portanto, a importância do emprego de fontes de Si no solo quando do cultivo dessa cultura, quando se deseja obter os benefícios desse elemento, conforme MA e TAKAHASHI (2002), independentemente da cultivar plantada.

Em uma diagnose foliar realizada aos 87 dias após o plantio das mudas notou-se que na variedade RB867515 havia incidência maior de sintomas de deficiência de B se comparada com a variedade SP81-3250 (Tabela 2). 
Tabela 2. Si acumulado e teor de Si em diferentes partes da cana em duas variedades de cana-de-açúcar em função de doses de Si aplicadas no solo

\begin{tabular}{|c|c|c|c|c|}
\hline \multirow{2}{*}{$\begin{array}{l}\text { Doses } \\
\mathrm{kg} \mathrm{ha}^{-1}\end{array}$} & \multicolumn{4}{|c|}{ Cultivar } \\
\hline & SP81- 3250 & RB86- 7515 & SP81- 3250 & RB86- 7515 \\
\hline \multirow[b]{3}{*}{0} & 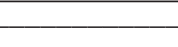 & +2 & 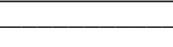 & 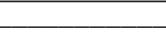 \\
\hline & \multicolumn{2}{|c|}{$\mathrm{Si}$ acumulado nos ponteiros (palmito + folhas) } & \multicolumn{2}{|c|}{ Teor de Si nos ponteiros (palmito + folhas) } \\
\hline & $2,49 \mathrm{a}$ & $1,20 \mathrm{~b}$ & 3,2 & 3,3 \\
\hline 100 & $2,59 \mathrm{a}$ & $1,30 \mathrm{~b}$ & 3,4 & 3,3 \\
\hline 200 & $2,28 \mathrm{a}$ & $1,57 \mathrm{~b}$ & 3,6 & 3,5 \\
\hline 400 & $2,75 \mathrm{a}$ & $1,47 \mathrm{~b}$ & 3,7 & 3,7 \\
\hline \multirow[t]{3}{*}{ Média } & $2,53 \mathrm{a}$ & $1,39 \mathrm{~b}$ & $3,5 \mathrm{a}$ & $3,5 \mathrm{a}$ \\
\hline & \multicolumn{2}{|c|}{$\begin{array}{c}\text { CV: } 20,5 \% \\
\text { dms (variedade): } 0,59 \\
\text { dms (média): } 0,29\end{array}$} & \multicolumn{2}{|c|}{$\begin{array}{c}\text { CV: } 10 \% \\
\text { dms (variedade): } 0,5 \\
\text { dms (média): } 0,3\end{array}$} \\
\hline & \multicolumn{2}{|c|}{ Si acumulado nas folhas abaixo dos ponteiros } & \multicolumn{2}{|c|}{ Teor de Si nas folhas abaixo dos ponteiros } \\
\hline 0 & $8,62 \mathrm{a}$ & $7,76 \mathrm{a}$ & 9,3 & 9,6 \\
\hline 100 & $12,01 \mathrm{a}$ & $8,06 \mathrm{~b}$ & 11,6 & 9,2 \\
\hline 200 & $13,00 \mathrm{a}$ & $8,90 \mathrm{~b}$ & 12,2 & 9,8 \\
\hline 400 & $11,84 \mathrm{a}$ & $11,63 \mathrm{a}$ & 12,1 & 13,5 \\
\hline \multirow[t]{3}{*}{ Média } & $11,37 \mathrm{a}$ & $9,09 \mathrm{~b}$ & $11,3 \mathrm{a}$ & $10,5 \mathrm{a}$ \\
\hline & \multicolumn{2}{|c|}{$\begin{array}{c}\text { CV: } 23,4 \% \\
\text { dms (variedade): } 3,51 \\
\text { dms (média): } 1,76\end{array}$} & \multicolumn{2}{|c|}{$\begin{array}{c}\text { CV: } 18,0 \% \\
\text { dms (variedade): } 2,9 \\
\text { dms (média): } 1,4\end{array}$} \\
\hline & \multicolumn{2}{|c|}{ Si acumulado nos colmos } & \multicolumn{2}{|c|}{ Teor de Si nos colmos } \\
\hline 0 & $2,54 \mathrm{a}$ & $2,02 \mathrm{a}$ & $1,0 \mathrm{a}$ & $1,0 \mathrm{a}$ \\
\hline 100 & $3,67 \mathrm{a}$ & $2,64 \mathrm{~b}$ & $1,3 \mathrm{a}$ & $1,2 \mathrm{a}$ \\
\hline 200 & $3,31 \mathrm{a}$ & $2,73 \mathrm{a}$ & $1,3 \mathrm{a}$ & $1,1 \mathrm{~b}$ \\
\hline 400 & $4,17 \mathrm{a}$ & $3,07 \mathrm{~b}$ & $1,8 \mathrm{a}$ & $1,4 \mathrm{~b}$ \\
\hline \multirow[t]{3}{*}{ Média } & $3,42 \mathrm{a}$ & $2,62 b$ & $1,4 \mathrm{a}$ & $1,2 \mathrm{~b}$ \\
\hline & \multicolumn{2}{|c|}{$\begin{array}{c}\text { CV: } 19,5 \% \\
\text { dms (variedade): } 0,86 \\
\text { dms (média): } 0,43\end{array}$} & \multicolumn{2}{|c|}{$\begin{array}{c}\text { CV: } 9,7 \% \\
\text { dms (variedade): } 0,2 \\
\text { dms (média): } 0,09\end{array}$} \\
\hline & \multicolumn{2}{|c|}{ Si acumulado na parte aérea total } & \multicolumn{2}{|c|}{ Número de folhas com deficiência de $\mathrm{B}^{* * *}$} \\
\hline 0 & 13,65 a & $10,97 \mathrm{a}$ & $8 \mathrm{a}$ & $12 \mathrm{a}$ \\
\hline 100 & $18,27 \mathrm{a}$ & $12,00 \mathrm{~b}$ & $4 \mathrm{a}$ & $13 \mathrm{~b}$ \\
\hline 200 & $18,58 \mathrm{a}$ & $13,19 \mathrm{~b}$ & $3 \mathrm{a}$ & $15 b$ \\
\hline 400 & $18,75 \mathrm{a}$ & $16,17 \mathrm{~b}$ & $6 \mathrm{a}$ & $13 \mathrm{~b}$ \\
\hline \multirow[t]{2}{*}{ Média } & $17,31 \mathrm{a}$ & $13,08 \mathrm{~b}$ & $5 \mathrm{a}$ & $13 \mathrm{~b}$ \\
\hline & \multicolumn{2}{|c|}{$\begin{array}{c}\text { CV: } 19 \% \\
\text { dms (variedade): } 4,24 \\
\text { dms (média): } 2,12\end{array}$} & \multicolumn{2}{|c|}{$\begin{array}{c}\text { CV: } 33,8 \% \\
\text { dms (variedade): } 4,41 \\
\text { dms (média): } 2,20 \\
\end{array}$} \\
\hline
\end{tabular}

Médias seguidas de letras iguais nas linhas não diferem entre si pelo teste de Tukey a 0,05 de significância.

*** Análise realizada aos 87 dias após o transplantio das mudas.

As duas cultivares de cana não diferiram entre si quanto ao teor de Si nos ponteiros e nas folhas abaixo do ponteiro, para nenhuma das doses desse elemento aplicadas (Tabela 2). No entanto, as concentrações médias de Si no palmito elevaram-se de 3,3 para 3,7 $\mathrm{g} \mathrm{kg}^{-1}$ e nas folhas abaixo do ponteiro de 9,4 $\mathrm{g}$ $\mathrm{kg}^{-1}$ para $12,8 \mathrm{~g} \mathrm{~kg}^{-1}$, na ausência de aplicação de Si e com fornecimento de $400 \mathrm{~kg} \mathrm{ha}^{-1}$ desse elemento respectivamente. Independentemente da cultivar, a concentração de Si nos ponteiros e nas folhas abaixo do ponteiro aumentou linearmente com as doses desse elemento (Figuras 4a, b). Quando se comparou a testemunha com a maior dose de Si $\left(400 \mathrm{~kg} \mathrm{ha}^{-1}\right)$, o aumento médio da concentração desse elemento nos ponteiros (palmito+folhas) e nas folhas abaixo do ponteiro foi de $36 \%$ e $12 \%$, respectivamente.

Segundo MA e TAKAHASHI (2002), a deposição de $\mathrm{Si}$, sob a forma de sílica, nas folhas das plantas contribui para melhorar a distribuição do manganês nos tecidos, prevenindo a toxidez por esse elemento; reduz perda de água por transpiração, aliviandoestresses hídricose salinos; contribui para a manutenção das folhas eretas; reduz efeitos adversos causados pelo excesso de nitrogênio, além de aumentar a resistência das plantas a estresses bióticos. 
(a)

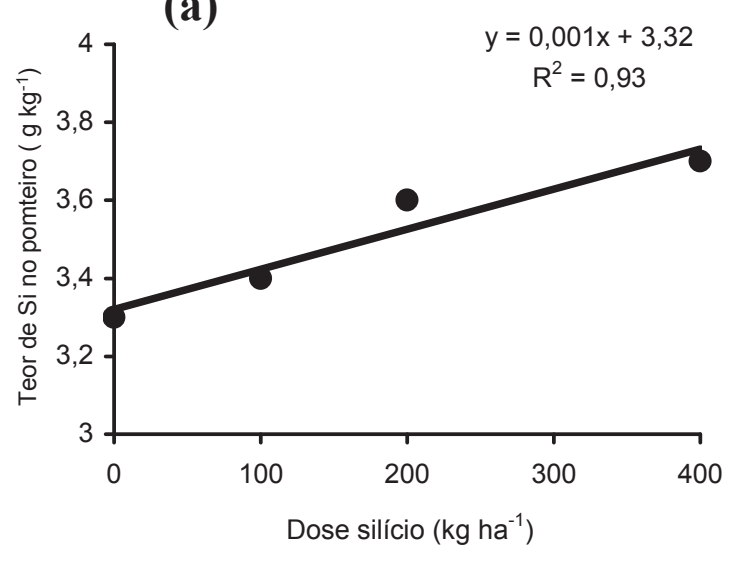

(b)

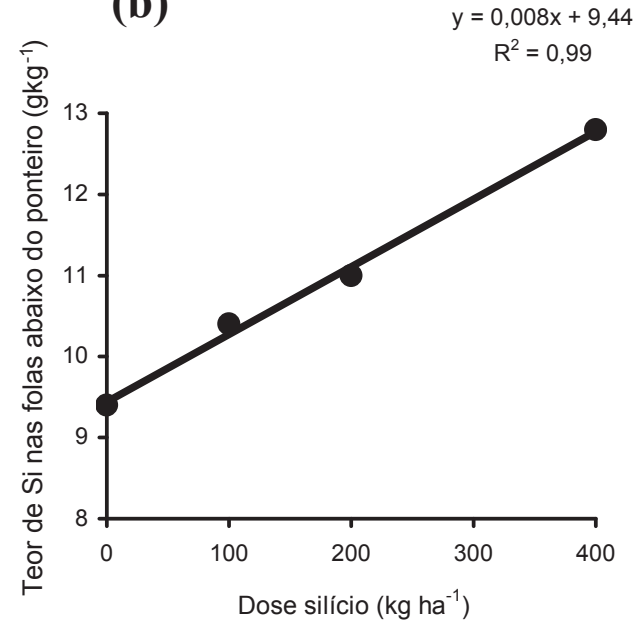

(c)

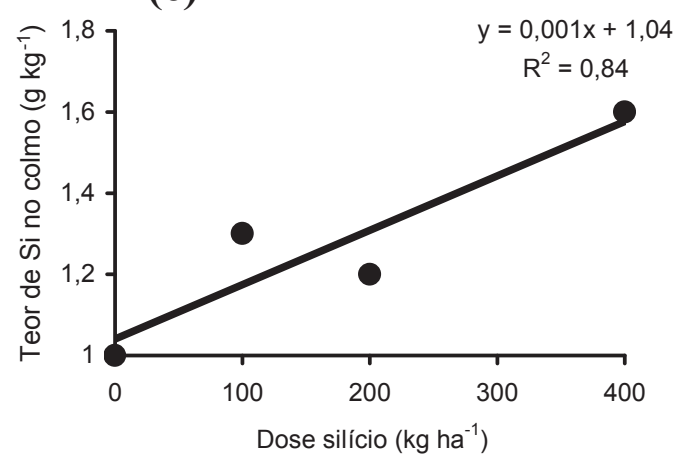

Figura 3. Teores de Si nos ponteiros (palmito+folhas) (a), nas folhas abaixo do ponteiro (b) e nos colmos (c) da cana em função de doses de Si aplicadas no solo (médias das duas variedades).

Na variedadeSP81-3250 observou-se teor deSinos colmos significativamente maior ao da variedade RB867515 (Tabela 2), em média 14\% mais alto. Considerando apenas as duas maiores doses de Si (200 e $\left.400 \mathrm{~kg} \mathrm{ha}^{-1}\right)$, (a)

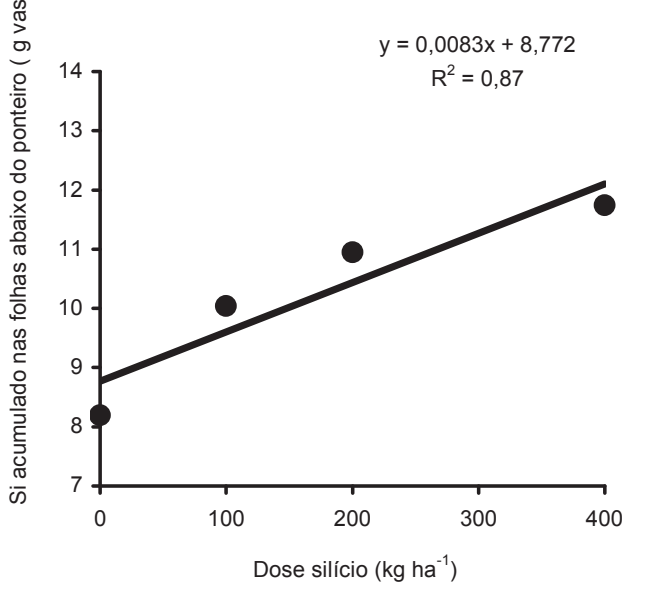

(b)

$y=0,0118 x+13,128$ $R^{2}=0,88$

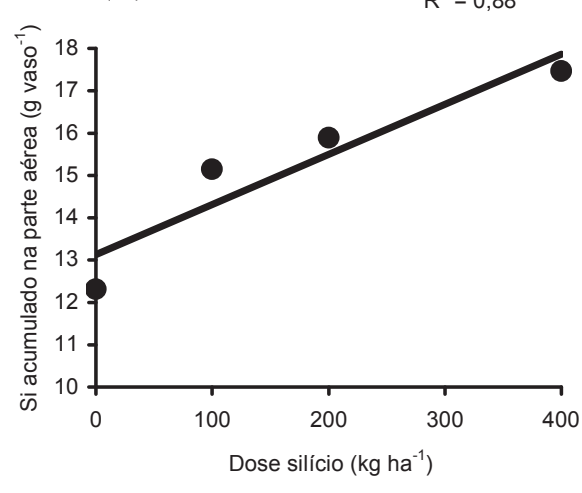

(c)

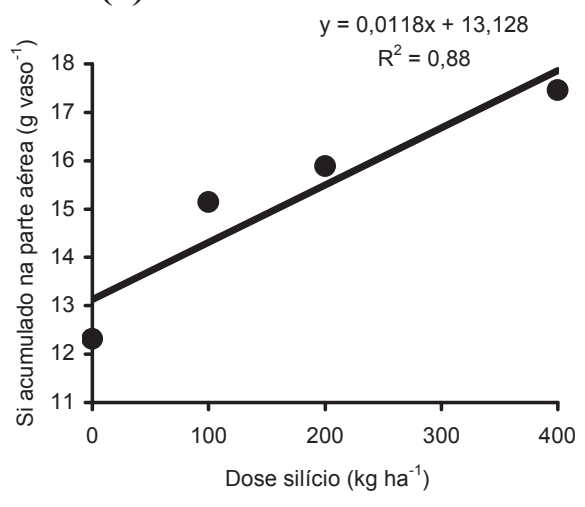

Figura 4. Si acumulado nas folhas abaixo do ponteiro (a), no colmo (b) e nas plantas (c) de duas cultivares de cultivares de cana-de-açúcar, conforme aplicação de doses crescentes desse elemento no solo (Médias das duas variedades).

a cultivar SP81-3250 concentrou, respectivamente, $15 \%$ e $22 \%$ mais $\mathrm{Si}$ nos colmos do que a RB86-7515 (Tabela 2). A deposição de sílica no colmo das plantas promove aumento da resistência ao acamamento ( $\mathrm{MA}_{\mathrm{A}}$ 
e TAKAHASHI, 2002). Essa característica é especialmente importante para a colheita da cana crua mecanizada. A seleção de variedades com alto potencial para absorção de Si poderia minimizar os problemas com tombamento na colheita mecanizada.

O teor médio de Si no colmo das duas cultivares de cana aumentou linearmente com as doses de Si aplicadas (Figura 4c). As plantas cultivadas na presença de $400 \mathrm{~kg} \mathrm{ha}^{-1} \mathrm{Si}$ apresentaram $60 \%$ mais Si no colmo do que aquelas mantidas na ausência de aplicação desse elemento. Tal resultado demonstra que a cana-de-açúcar realmente responde a aplicação de doses de Si no solo.

Além da resistência ao acamamento ( $\mathrm{MA}_{\mathrm{A}} \mathrm{e}$ TAKAHASHI, 2002), a deposição de Si no colmo da canade-açúcar resultou no controle da broca do colmo (KorNDÖRFER, et al. 2002). Nesse contexto, fica patente a importância do emprego de fontes de Si no seu cultivo, sobretudo quando ocorre dá em solos pobres nesse elemento ou em solos onde o Si não está disponível.

\section{CONCLUSÕES}

1. A aplicação de escória de siderurgia (silicato) aumentou o teor de Si disponível no solo e o teor foliar da cana-de-açúcar.

2. Boa parte do Si absorvido pela parte aérea da cana foi proveniente do fertilizante aplicado, e a variedade de cana SP81-3250 aproveitou melhor o Si proveniente do silicato se comparado com a variedade RB86-7515.

\section{REFERÊNCIAS}

BERNI, F. R.; PRABHU, S. A. Eficiência relativa de fontes de silício no controle de brusone nas folhas de arroz. Pesquisa Agropecuária Brasileira, v.38, p.195-201, 2003.

BRASIL. Ministério da Agricultura, Pecuária e Abastecimento. Balanço nacional da cana-de-açúcar e agroenergia. Brasília, DF, 2007. 140 p.

CARVALHO-PUPATTO, J.G.; BULL, L.T.; CRUSCIOL, C.A.C.; MAUAD, M.; SILVA, R. H. Efeito de escória de alto forno no crescimento radicular e na produtividade de arroz. Pesquisa Agropecuária Brasileira, v.38, p.1323-1328, 2003.

EMPRESA BRASILEIRA DE PESQUISA AGROPECUÁRIA. Centro Nacional de Pesquisa de Solos. Manual de métodos de análise de solo. 2.ed. rev. atual. Rio de Janeiro, Embrapa Solos, 212p. 1999.

EMPRESA BRASILEIRA DE PESQUISA AGROPECUÁRIA. Centro Nacional de Pesquisa de Solos. Sistema brasileiro de classificação de solos. 2.ed. Rio de Janeiro: Embrapa Solos, 2006. 306p.
FERREIRA, D.F. Análises estatísticas por meio do Sisvar para Windows versão 4.0. In: REUNIÃO ANUAL DA REGIÃO BRASILEIRA DA SOCIEDADE INTERNACIONAL DE BIOMETRIA, 45., 2000, São Paulo. Anais... São Paulo: UFSCar, 2000. p.255-258.

JAN, M.S. A cana de açúcar, de etanol e de eletricidade: uma commodity global. Disponível em: http:/ / www.unica.com.br/ opiniao/show.asp. Acesso em: 4/9/2008.

KORNDÖRFER, G.H.; DATNOFF, L.E. Adubação com silício: uma alternativa no controle de doenças da cana-de-açúcar e do arroz. Informações Agronômicas, v.70, p.1-5, 1995.

KORNDÖRFER, G.H.; ARANTES, V.A.; CORRÊA, G.F.; SNYDER, G.H. Efeito da aplicação de silicato de cálcio em solos cultivados com arroz de sequeiro. Revista Brasileira de Ciência do Solo, v.23, p.623-629, 1999.

KORNDÔRFER, G.H.; PEREIRA, H.S.; CAMARGO, M.S. Silicatos de cálcio e magnésio na agricultura. 2.ed. Uberlândia, GPSi / ICIAG/UFU, 2002. 24p. (Boletim Técnico, 1)

KORNDÖRFER, G.H; PEREIRA, H.S.; CAMARGO, M.S. Silicato de cálcio e magnésio na agricultura. 3 ed. Uberlândia: UFU/ICIAG, 2004b. 28 p. (Boletin Técnico, 2)

KORNDÖRFER, G.H.; PEREIRA. H. S.; NOLLA. A. Análise de silício: solo, planta e fertilizante. Uberlândia: GPSi / ICIAG/ UFU, 2004a. 34 p. (Boletim Técnico, 2)

KORNDÖRFER, G.H.; RAMOS, L.A. Diagnose Foliar em Cana-de-açúcar. In: PRADO, R.M.; ROZANE, D.E.; VALE, D.W.; CORREIA, M.A.R. ; SOUZA, H.A. Nutrição de plantas: diagnose foliar em grandes culturas. 1.ed. Jaboticabal: FCAV / CAPES/FUNDUNESP, 2008. v.1. 301p.

MA, J.F.; TAKAHASHI, E. Soil, fertilizer and plant silicon research in Japan. Amsterdan: Elsevier Science, 2002. 281p.

PEREIRA, H.S.; KONDÖRFER, G.H.; VIDAL, A.A.; CAMARGO, M.S. Fontes de silício para a cultura do arroz. Scientia Agricola, v.16, p.522-528, 2004.

PRADO, R.M.; FERNANDES, F.M. Uso agrícola da escória de siderurgia no Brasil: estudo na cultura da cana-de-açúcar. Jaboticabal: FUNEP, 2001. 67p.

RAIJ, B. van.; CANTARELA, H.; QUAGGIO, J.A.; FURLANI, A.M.C. (Eds.). Recomendações de adubação e calagem para o Estado de São Paulo. 2.ed. Campinas, SP: Instituto Agronômico \& Fundação IAC, 1996. 285p.

SAVANT, N.K.; KORNDÖRFER G.H.; SNYDER, G.H.; DATNOFF, L.E. Silicon nutrition and sugarcane production: A review. Journal of Plant Nutrition, v.12, p.1853-1903, 1999. 